\title{
Size approval voting
}

Citation for published version (APA):

Alcalde-Unzu, J., \& Vorsatz, M. (2007). Size approval voting. METEOR, Maastricht University School of Business and Economics. METEOR Research Memorandum No. 008 https://doi.org/10.26481/umamet.2007008

Document status and date:

Published: 01/01/2007

DOI:

10.26481/umamet.2007008

Document Version:

Publisher's PDF, also known as Version of record

\section{Please check the document version of this publication:}

- A submitted manuscript is the version of the article upon submission and before peer-review. There can be important differences between the submitted version and the official published version of record.

People interested in the research are advised to contact the author for the final version of the publication, or visit the DOI to the publisher's website.

- The final author version and the galley proof are versions of the publication after peer review.

- The final published version features the final layout of the paper including the volume, issue and page numbers.

Link to publication

\footnotetext{
General rights rights.

- You may freely distribute the URL identifying the publication in the public portal. please follow below link for the End User Agreement:

www.umlib.nl/taverne-license

Take down policy

If you believe that this document breaches copyright please contact us at:

repository@maastrichtuniversity.nl

providing details and we will investigate your claim.
}

Copyright and moral rights for the publications made accessible in the public portal are retained by the authors and/or other copyright owners and it is a condition of accessing publications that users recognise and abide by the legal requirements associated with these

- Users may download and print one copy of any publication from the public portal for the purpose of private study or research.

- You may not further distribute the material or use it for any profit-making activity or commercial gain

If the publication is distributed under the terms of Article $25 \mathrm{fa}$ of the Dutch Copyright Act, indicated by the "Taverne" license above, 
Jorge Alcalde-Unzu, Marc Vorsatz

Size Approval Voting

$\mathrm{RM} / 07 / 008$

JEL code: D71

\section{METE@R}

Maastricht research school of Economics of TEchnology and ORganizations

Universiteit Maastricht

Faculty of Economics and Business Administration P.O. Box 616

NL - 6200 MD Maastricht

phone : ++31433883830

fax : ++31433884873 



\title{
Size Approval Voting
}

\author{
Jorge Alcalde-Unzu* and Marc Vorsatz ${ }^{\dagger}$
}

March 14, 2007

\begin{abstract}
We propose a new class of voting rules, called Size Approval Voting. According to this rule, the effective weight of a vote from a given individual depends on how many other alternatives the very same individual votes for. In particular, weights are assumed to be non-negative and weakly decreasing in the number of approved alternatives. Then, for a given profile of individual votes, all those alternatives with the maximal sum of weighted votes are elected. We show in our axiomatic analysis that the family of all Size Approval Voting is characterized by a set of natural properties.
\end{abstract}

Keywords: Approval Voting, Characterization.

JEL-Number: D71.

\section{Introduction}

In a lot of social choice settings individual preferences on the set of alternatives are not extracted by means of a direct revelation mechanism, instead individuals are asked to vote for one or more of the alternatives that stand for election. The winning alternative(s) is (are) then determined by means of a voting rule, an aggregator of the individual voting decisions.

*Corresponding Author. Departamento de Economía, Universidad Pública de Navarra, 31006 Pamplona, Spain. E-mail: jorge.alcalde@unavarra.es

${ }^{\dagger}$ Department of Economics, Maastricht University, P.O. Box 616, 6200 MD Maastricht, The Netherlands. E-mail: m.vorsatz@algec.unimaas.nl 
Approval Voting, introduced by Brams and Fishburn [4], is one of the most important voting rules both in theory and practice. According to it, every individual can vote for as many alternatives as $\mathrm{s} /$ he wishes to and all alternatives with the highest number of votes are elected. One critique on Approval Voting has been its indeterminacy; that is, for most ordinal preference profiles, any alternative could possibly win the election (see Saari and van Newenhizen [15] and [16]). The underlying intuition of this result is that, in this case, the set of undominated (sincere) strategies under Approval Voting rather large and, therefore, it is impossible to know a priori which set of alternatives an individual finally votes for. Brams et al. [6] argue however that the indeterminacy of Approval Voting is not a major drawback, simply because the actual voting decisions reveal some information about cardinal utilities. For cardinal utilities, at least two different definitions of sincerity have been provided. The weak version of sincerity - if some alternative is approved all alternatives that give a higher cardinal utility should also be approved - has been characterized by Brams and Fishburn [5] and Nurmi [14]. The strong version of sincerity - an alternative is approved if and only if its cardinal utility is higher than average cardinal utility of all alternatives - has been studied by Hoffman [10], Merrill [12], Merrill and Nagel [13], and Ballester and Rey-Biel [3]. In fact, the latter authors show that if an individual does not have any information about the preferences of others and the electorate is large, then s/he will be strongly sincere under Approval Voting.

The amount of cardinal information individuals can transmit through their votes depends on the proper voting rule. For example, if the Plurality Rule was applied instead of Approval Voting, individuals will, under the same assumptions as above, always vote for their best alternative as above and, consequently, no information about the utility of the second best alternative is collected. Since in different situations society may want to take into account distinct degrees of information about cardinal utilities, it is our objective to characterize axiomatically a general class of voting rules that allows 
the decision maker to vary the individual incentives to approve alternatives beyond their best alternative. ${ }^{1}$

The class of voting rules we propose, Size Approval Voting, is as follows: Assign a non-negative weight to each vote depending on the number of alternatives this individual votes for. In particular, weights are assumed to be weakly decreasing in the number of approved alternatives. Then, for all profiles of individual votes, the alternatives with the highest sum of weighted votes are elected. It is easy to see that the class of all Size Approval Voting encompasses a variety of well-known voting rules. It reduces to a $k$-Approval Voting if the weight is zero for all subsets larger than $k$ and strictly positive and identical for all subsets with a size of at most $k$. Observe that the Plurality Rule and Approval Voting correspond to the extreme cases of a $k$-Approval Voting and, therefore, they are included in our family.

To see why the class of all Size Approval Voting can be thought of as a variety of possibilities of incorporating cardinal information in the aggregation process, consider again the case of three alternatives. If we exclude the special case of the constant rule (always elect all alternatives), any Size Approval Voting is representable by the vector of weights $w=(1, p, 0)$, where $p \in[0,1]$. Here, $p$ refers to the weight of each vote of an individual who approves exactly two alternatives. If $p=0$, individuals will only approve one alternative. This rule corresponds therefore to the Plurality Rule. In the other extreme, $p=1$, the rule coincides with Approval Voting. Consequently, under the same assumptions of complete uncertainty as presented by Ballester and Rey-Biel [3], higher values of $p$ induce more incentives to approve the second best alternative since the cost of approving one more alternative gets smaller. However, higher values of $p$ imply also that the voting rule ignores in the aggregation process the possibly not small differences in the utility of the two voted alternatives.

\footnotetext{
${ }^{1}$ As a simple example consider the case when there are three complementary alternatives for election. In a single-seat election, the Plurality Rule would do fine. However, in a multi-seat election the information Approval Voting provides about the utility of second best alternative may just be too important to be missed.
} 
In our axiomatic analysis, we are interested in general voting procedures that could operate in different voting situations in which the set of voters might vary (for instance, different choices have to be made over time). In particular, and given a universal set of potential voters, a voting procedure should specify an outcome (a non-empty subset of the given set of alternatives) for every electorate (the subset of voters that indeed vote). In this setting, we apply the following properties in order to characterize all Size Approval Voting: First, Consistency in Voters states that (i) if an alternative is not elected by some electorate and does not receive any vote from a disjoint electorate, then the alternative is not elected whenever the two electorates are assembled and (ii) if a common subset of alternatives is elected by two disjoint electorates, then exactly this set of alternatives has to be elected whenever all individuals within and no individual outside these two electorates participates in the election. Second, Anonymity is symmetry across voters. Third, Neutrality is symmetry across alternatives. Fourth, Contraction states that if one individual reduces the set of alternatives $\mathrm{s} /$ he approves and some of the alternatives this individual still votes for have been elected originally, then, at the new situation, these alternatives are still elected and no alternative that originally has not been elected gets elected. Fifth, NoVeto means that no electorate is able to change completely the opinion of a sufficiently large sequence of electorates with the same opinion.

Our work also contributes to the already existing literature on axiomatic voting theory. Among others, Fishburn [7] and [8], Sertel [17], Baigent and $\mathrm{Xu}$ [2], Goodin and List [9], and Vorsatz [19] study the axiomatic properties of Approval Voting. Alós-Ferrer [1] shows that the axioms in the characterization in [7] are not independent. Finally, to our best knowledge, the only existing attempt to generalize Approval Voting is due Massó and Vorsatz [11]. The authors relax the neutrality axiom and characterize the class of all Weighted Approval Voting. This class of voting rule takes as given a strictly positive weight for every alternative and a complete preorder (a complete, reflexive, and transitive binary relation) on the set of alternatives. Now, given 
a profile of individual votes, the alternative for which the product of ex-ante weight times the number of votes is maximal is elected. In case the product is maximal for more than one alternative the complete preorder is applied as a tie-breaking rule.

We proceed as follows: In the next section, we introduce basic notation and definitions. Afterwards, we present and discuss the properties that we use in our characterization. In Section 4, we prove our main result and, in Section 5, we establish the independence of the axioms.

\section{Notation and Definitions}

We consider situations in which a set of individuals, which is taken to be variable, has to decide upon the election of a subset of a given set of alternatives. Formally, let $X$ be the set of alternatives for election. Generic alternatives will be denoted by $x, y$, and $z$, larger subsets of $X$ by $S$ and $T$. The cardinality of $X,|X|$, is finite and greater or equal to 2. We represent the universal set of individuals by the set of natural numbers $\mathbb{N}$. The set of individuals actually participating in the election, the electorate $N$, is a finite subset of the natural numbers. Often we will also use the capital letters $A$ and $B$ to denote electorates.

For any individual $i \in \mathbb{N}$, let $M_{i} \in 2^{X}$ be the set of alternatives $i$ votes for. A profile $M=\left(M_{i}\right)_{i \in \mathbb{N}} \in\left(2^{X}\right)^{\mathbb{N}}$ is a list of all votes. Given a profile $M$ and an electorate $N$, a response profile $M_{N}=\left(M_{i}\right)_{i \in N} \in\left(2^{X}\right)^{N}$ is the $n$-tuple of votes coming from the electorate $N$ at profile $M$. We say that the response profiles $M_{A}$ and $M_{B}^{\prime}$, corresponding to the electorates $A$ and $B$ of equal size, are isomorphic if there exists a one-to-one mapping $\pi: A \rightarrow B$ such that for all $i \in A, M_{i}=M_{\pi(i)}^{\prime}$. Given two disjoint electorates $A$ and $B$ and two response profiles $M_{A}$ and $M_{B}$, denote by $M_{A}+M_{B}$ the response profile $\left(M_{i}\right)_{i \in A \cup B} \in\left(2^{X}\right)^{A \cup B}$. Finally, given a response profile $M_{N}$, a set of maximal sub-electorates is taken to be a partition $N_{1}, \ldots, N_{n}$ of $N$ such that for all $N_{m}$ with $m \in\{1, \ldots, n\}$ it is the case that $M_{k} \cap M_{l}=\emptyset$ for all 
$k, l \in N_{m}$ and $\left(\bigcup_{i \in N_{m}} M_{i}\right) \cap M_{k} \neq \emptyset$ for all $k \notin N_{m}$. Intuitively, a set of maximal sub-electorates decomposes $N$ into subgroups of individuals with the property that in each subgroup every alternative receives at most one vote and it is impossible to construct a coarser partition of $N$.

Given an electorate $N$, a voting rule $v^{N}:\left(2^{X}\right)^{N} \rightarrow\left(2^{X} \backslash \emptyset\right)$ selects for all profiles $M$ a nonempty set of feasible alternatives $v^{N}(M)$ with the property that for all $M, M^{\prime} \in\left(2^{X}\right)^{\mathbb{N}}$ such that $M_{N}=M_{N}^{\prime}, v^{N}(M)=v^{N}\left(M^{\prime}\right)$. Then, with a slight abuse of notation, we will write $v\left(M_{N}\right)$ instead of $v^{N}(M)$. A family of voting rules $\left\{v^{N}:\left(2^{X}\right)^{N} \rightarrow 2^{X} \backslash \emptyset\right\}_{N}$ is a set of voting rules, one for every electorate $N$. It is denoted by $v$. Finally, given a response profile $M_{N}$ and a permutation $\mu: X \rightarrow X$, let $\mu\left(M_{N}\right)$ and $\mu\left(v\left(M_{N}\right)\right)$ be the response profile and the set of elected alternatives obtained when alternatives are permuted according to $\mu$.

To define the class of all Size Approval Voting, let $\mathbb{R}_{+}$and $\mathbb{R}_{++}$be the sets of non-negative and strictly positive real numbers, respectively. Similarly, let $\mathbb{Q}$ be the set of rational numbers. Given $k \in \mathbb{N}$ such that $0<k \leq|X|$, the response profile $M_{N}$, and alternative $x \in X, G^{k}\left(M_{N}, x\right)=\mid\{i \in N$ : $x \in M_{i}$ and $\left.\left|M_{i}\right|=k\right\} \mid$ denotes the support of size $k$ to $x$ at $M_{N}$. Then, $G_{x}\left(M_{N}\right)=\sum_{k=1}^{|X|} G^{k}\left(M_{N}, x\right)$ is referred to as the support of $x$ at $M_{N}$. Finally, given a response profile $M_{N}$, two alternatives $x, y \in X$, and two natural numbers $k, l \in\{1, \ldots,|X|\}, F_{x, y}\left(M_{N} ; k, l\right)=\frac{G^{k}\left(M_{N}, x\right)}{G^{l}\left(M_{N}, y\right)}$ denotes the relative support of size $k$ to $x$ at $M_{N}$ with respect the support of size $l$ to $y$ at $M_{N}$.

Definition 1 The family of voting rules $v$ is a Size Approval Voting if there exists a vector of weights $w=\left(w_{k}\right)_{k \leq|X|}$, with $w_{k} \in \mathbb{R}_{+}$and $w_{k} \geq w_{k+1}$ for all $k$, such that for all profiles $M \in\left(2^{X}\right)^{\mathbb{N}}$ and all electorates $N$,

$$
x \in v\left(M_{N}\right) \Leftrightarrow \sum_{k=1}^{|X|} w_{k} \cdot G^{k}\left(M_{N}, x\right) \geq \sum_{k=1}^{|X|} w_{k} \cdot G^{k}\left(M_{N}, y\right) \text { for all } y \in X .
$$

The class of all Size Approval Voting encompasses some well known families of voting rules. For example, if there exists a $p \in\{1, \ldots,|X|\}$ such that $w_{k}=w_{k-1}>0$ for all $k \leq p$ and $w_{l}=0$ for all $w_{l}>p$, then the considered 
family of voting rules is a $p$-Approval Voting; that is, votes are effective if and only if an individual approves at most $p$ alternatives. Approval Voting $(p=|X|)$ and the Plurality Rule $(p=1)$ are special cases of a $p$-Approval Voting. The constant rule is obtained when $w_{k}=0$ for all $k \in\{1, \ldots,|X|\}$.

\section{Properties and Characterization}

In this section, we introduce the axioms and present our main Theorem. The following consistency property requires the satisfaction of two conditions. First, if an alternative is not elected from an electorate $A$ and it does not receive any vote from the disjoint electorate $B$, then it should be not elected if the two electorates are assembled. Second, if two disjoint electorates elect some common alternatives, then exactly these alternatives are elected when whenever all individuals within and no individual outside these two electorates participates in the election. The latter condition has been suggested first by Smith [18].

Consistency IN Voters: The family of voting rules $v$ is consistent in voters if for all profiles $M \in\left(2^{X}\right)^{\mathbb{N}}$ and all disjoint electorates $A, B \subset \mathbb{N}$,

(i) $x \notin v\left(M_{A}\right)$ and $x \notin M_{i}$ for all $i \in B \Rightarrow x \notin v\left(M_{A}+M_{B}\right)$

(ii) $v\left(M_{A}\right) \cap v\left(M_{B}\right) \neq \emptyset \Rightarrow v\left(M_{A}+M_{B}\right)=v\left(M_{A}\right) \cap v\left(M_{B}\right)$.

Anonymity states that the set of elected alternatives is immune to permutations of individuals.

AnONYMity: The family of voting rules $v$ is anonymous if for all isomorphic response profiles $M_{A}$ and $M_{B}^{\prime}$,

$$
v\left(M_{A}\right)=v\left(M_{B}^{\prime}\right)
$$

Similarly, Neutrality requires that the labels of the alternatives do not matter.

Neutrality: The family of voting rules $v$ is neutral if for all profiles $M \in$ $\left(2^{X}\right)^{\mathbb{N}}$, all electorates $N$, and all permutations $\mu: X \rightarrow X$, 


$$
\mu\left(v\left(M_{N}\right)\right)=v\left(\mu\left(M_{N}\right)\right) .
$$

The next property, contraction, considers the situation when one individual reduces the set of alternatives s/he votes for. In particular, it is asked that if some of the alternatives in the reduced set were elected in the original situation, then these alternatives are still elected and any alternative that has not been elected originally is still not elected.

Contraction: The family of voting rules $v$ satisfies contraction if for all profiles $M, M^{\prime}$ and all electorates $N$ such that $M_{j}^{\prime} \subseteq M_{j} \subsetneq X$ for some $j \in N$, $M_{i}=M_{i}^{\prime}$ for all $i \in(N \backslash\{j\})$, and $v\left(M_{N}\right) \cap M_{j}^{\prime} \neq \emptyset$,

$$
M_{j}^{\prime} \cap v\left(M_{N}\right) \subseteq v\left(M_{N}^{\prime}\right) \subseteq v\left(M_{N}\right) .
$$

The last property, No-Veto, states that if there exists a succession of disjoint electorates such that $S$ is the set of elected alternatives for each electorate, the addition of any outside electorate in which no alternative of $S$ is elected to a sufficiently large number of the former electorates is not able to change totally the original set of elected alternatives.

No-Veto: The family of voting rules $v$ satisfies no-veto if for all profiles $M \in$ $\left(2^{X}\right)^{\mathbb{N}}$, all successions of disjoint electorates $\left\{N_{i}\right\}_{i \in \mathbb{N}}$ such that $v\left(M_{N_{i}}\right)=S$ for all $i \in \mathbb{N}$, and any other electorate $A$ for which $A \cap N_{i}=\emptyset$ for all $i \in \mathbb{N}$ and $v\left(M_{A}\right) \cap S=\emptyset$, there exists an integer $k \in \mathbb{N}$ such that

$$
v\left(M_{N_{1}}+M_{N_{2}}+\ldots+M_{N_{k}}+M_{A}\right) \cap S \neq \emptyset .
$$

The main result of our paper is a characterization of the family of all Size Approval Voting by means of these properties.

Theorem 1 The family of voting rules $v$ satisfies Consistency in Voters, Anonymity, Neutrality, Contraction, and No-Veto if and only if $v$ is a Size Approval Voting. 


\section{Proof of the Theorem}

In this section, we present the proof of our main result. Lemma 1 shows that there exists a non-negative real number $p$ such that if an electorate consists of an unique individual who votes for more than $p$ alternatives, then the set of elected alternatives by $v$ is $X$, whereas the set of approved alternatives by the individual is elected by $v$ if this set has at most $p$ alternatives.

Lemma 1 Suppose that the family of voting rules $v$ satisfies Consistency in Voters, Anonymity, Neutrality, Contraction, and No-Veto. Then, there exists a $p \in[0,|X|)$ such that for all profiles $M$ and all $i \in \mathbb{N}$ (i) $\left|M_{i}\right|>p$ if and only if $v\left(M_{i}\right)=X$ and (ii) $0<\left|M_{i}\right| \leq p$ if and only if $v\left(M_{i}\right)=M_{i}$.

Proof: Take any $v$ that satisfies the hypothesis of the Lemma. Consider any profile $M$ and any individual $i \in \mathbb{N}$ such that $M_{i} \neq \emptyset$. By Neutrality and the fact that $v\left(M_{i}\right) \neq \emptyset, v\left(M_{i}\right) \in\left\{\left\{M_{i}\right\},\left\{X \backslash M_{i}\right\},\{X\}\right\}$. To show that $v\left(M_{i}\right) \neq\left(X \backslash M_{i}\right)$, suppose otherwise. We consider two different cases:

(i) Suppose that $\left|M_{i}\right| \geq \frac{|X|}{2}$. If $M_{i}=X$, then $v\left(M_{i}\right)=X$ by Neutrality. If $M_{i} \neq X$, take any $T \subset X$ such that $|T|=\left|M_{i}\right|$ and $(X \backslash T) \cap\left(X \backslash M_{i}\right)=\emptyset$. Such a set $T$ must exist. Consider now any profile $M^{\prime}$ such that $M_{1}^{\prime}=M_{i}$ and $M_{j}^{\prime}=T$ for all $j \neq 1$. By Anonymity, $v\left(M_{1}^{\prime}\right)=v\left(M_{i}\right)=\left(X \backslash M_{i}\right)$. Anonymity, Neutrality, and the assumption $v\left(M_{i}\right)=\left(X \backslash M_{i}\right)$ imply together that $v\left(M_{j}^{\prime}\right)=(X \backslash T)$ for all $j \neq 1$. Thus, $v\left(M_{1}^{\prime}\right) \cap v\left(M_{j}^{\prime}\right)=\emptyset$ for all $j \neq 1$. Consequently, by No-Veto, there exists $t \in \mathbb{N}$ such that $(X \backslash T) \cap v\left(M_{2}^{\prime}+\ldots+\right.$ $\left.M_{t}^{\prime}+M_{1}^{\prime}\right) \neq \emptyset$. However, given that $(X \backslash T) \cap v\left(M_{1}^{\prime}\right)=\emptyset$ by construction and that for all $x \in(X \backslash T), x \notin M_{j}^{\prime}$ for all $j \in\{2, \ldots, t\}$, it follows from the first part of Consistency in Voters that $(X \backslash T) \cap v\left(M_{2}^{\prime}+\ldots+M_{t}^{\prime}+M_{1}^{\prime}\right)=\emptyset$. This is a contradiction and, therefore, $v\left(M_{i}\right) \in\left\{\left\{M_{i}\right\},\{X\}\right\}$ whenever $\left|M_{i}\right| \geq \frac{|X|}{2}$.

(ii) Suppose that $\left|M_{i}\right|<\frac{|X|}{2}$. Consider any profile $M^{\prime}$ such that $X \neq$ $M_{i}^{\prime} \supseteq M_{i}$ and $\left|M_{i}^{\prime}\right|>\frac{|X|}{2}$, which is obviously possible. By the former case, $v\left(M_{i}^{\prime}\right) \in\left\{\left\{M_{i}^{\prime}\right\},\{X\}\right\}$; that is, $M_{i}^{\prime} \subseteq v\left(M_{i}^{\prime}\right)$. Hence, $M_{i} \cap v\left(M_{i}^{\prime}\right)=M_{i}$. So, we 
can apply Contraction to obtain that $M_{i} \subseteq v\left(M_{i}\right)$. Hence, $v\left(M_{i}\right) \neq\left(X \backslash M_{i}\right)$ whenever $\left|M_{i}\right|<\frac{|X|}{2}$.

We can deduce from part (i) and (ii) that $v\left(M_{i}\right) \neq\left(X \backslash M_{i}\right)$. Thus, it remains to be shown that for all profiles $M$ and all individuals $i, j \in \mathbb{N}$ such that $\left|M_{j}\right| \geq\left|M_{i}\right|$ and $v\left(M_{i}\right)=X, v\left(M_{j}\right)=X$. Suppose otherwise; that is, $v\left(M_{j}\right)=M_{j}$. Take any profile $M^{\prime}$ such that $\left|M_{j}^{\prime}\right|=\left|M_{i}\right|$ and $M_{j}^{\prime} \subseteq M_{j}$. By Neutrality and Anonymity, $v\left(M_{j}^{\prime}\right)=X$. Now, since $M_{j}^{\prime} \cap v\left(M_{j}\right)=M_{j}^{\prime}$, we can apply Contraction to obtain that $M_{j}^{\prime} \subseteq v\left(M_{j}^{\prime}\right) \subseteq v\left(M_{j}\right)$. But this cannot be because $v\left(M_{j}\right)=M_{j} \subset X=v\left(M_{j}^{\prime}\right)$.

From now on, let $p \in[0,|X|)$ be any real number that satisfies the implications of Lemma 1. We show in Lemma 2 that any alternative that does not receive any support is not elected (except when no alternative receives any support of size lower than $p$ ).

Lemma 2 Suppose that the family of voting rules $v$ satisfies Consistency in Voters, Anonymity, Neutrality, Contraction, and No-Veto. Then, for all profiles $M$ and electorates $N$ such that $G_{y}\left(M_{N}\right)=0$ for some $y \in X$ and $G^{k}\left(M_{N}, x\right)>0$ for some $x \in X$ and $k \leq p, y \notin v\left(M_{N}\right)$.

Proof: Take any $v$ that satisfies the hypothesis of the Lemma. Let the profile $M$ and the electorate $N$ be such that there exists an individual $i \in \mathbb{N}$ such that $\left|M_{i}\right| \leq p$ and $x \in M_{i}$. Then, by Lemma $1, v\left(M_{i}\right)=M_{i}$. Now, we have two possibilities: If $N=\{i\}$, it is obvious that $y \notin v\left(M_{i}\right)$. Suppose therefore that $N \neq\{i\}$. Given that $y \notin v\left(M_{i}\right)$ and $G_{y}\left(M_{N}\right)=0$, it follows from the first part of Consistency in Voters that $y \notin v\left(M_{i}+M_{N \backslash\{i\}}\right)=v\left(M_{N}\right)$.

Proof of Theorem 1: It is immediate to see that any Size Approval Voting satisfies Consistency in Voters, Anonymity, Neutrality, Contraction, and NoVeto. Therefore, consider any family of voting rules $v$ that satisfies these properties. We have to show that there exists a vector of weights $w=$ $\left(w_{k}\right)_{k \leq|X|}$, with $w_{k} \in \mathbb{R}_{+}$and $w_{k} \geq w_{k+1}$ for all $k \in\{1, \ldots,|X|-1\}$, such that for all profiles $M \in\left(2^{X}\right)^{\mathbb{N}}$ and all electorates $N, x \in v\left(M_{N}\right) \Leftrightarrow \sum_{k=1}^{|X|} w_{k}$. 
$G^{k}\left(M_{N}, x\right) \geq \sum_{k=1}^{|X|} w_{k} \cdot G^{k}\left(M_{N}, y\right)$ for all $y \in X$. To do so, we consider different cases.

(A) Suppose that for all profiles $M$ and all electorates $N, v\left(M_{N}\right)=X$. Then, the vector of weights $w=\left(w_{1}, \ldots, w_{|X|}\right)$ has to be such that $w_{j}=0$ for all $j=1, \ldots,|X|$.

(B) Suppose that there exists a profile $M$ and an electorate $N$ such that $v\left(M_{N}\right) \neq X$. We divide the corresponding analysis into four subcases and analyze the restrictions different response profiles impose on the weights. It follows from Lemma 1 together with the second part of Consistency in Voters that we can exclude from our considerations all individuals that approve more than $p$ alternatives. Hence, the weights $w_{p+1}, \ldots, w_{|X|}$ have to be zero.

(1) Let the response profile $M_{N}$ be such that $\left|M_{i}\right|=0$ for all $i \in N$. By the definition of $v, v\left(M_{N}\right) \neq \emptyset$. Then, by Neutrality, $v\left(M_{N}\right)=X$. It is obvious that this situation does not impose any additional restriction on the weights. Because of this case and the second part of Consistency in Voters we can also ignore in the rest of the analysis all individuals that do not approve any alternative.

(2) Let the response profile $M_{N}$ be such that $\left|M_{i}\right|=k$ for all $i \in N$ for some $0<k \leq p$. We consider two subcases. (a) Suppose that $M_{i} \cap M_{j}=\emptyset$ for all $i, j \in N$. By Lemma 2, any alternative $x \notin \bigcup_{i \in N} M_{i}$ does not belong to $v\left(M_{N}\right)$. Since all individuals approve the same number of alternatives we can apply Neutrality to obtain that $v\left(M_{N}\right)=\bigcup_{i \in N} M_{i}$. (b) If there are two individuals $i, j \in N$ such that $M_{i} \cap M_{j} \neq \emptyset$, consider a set of maximal sub-electorates $N_{1}, \ldots, N_{n}$. Since this partition of $N$ is constructed in such a way that every alternative receives from every sub-electorate at most one vote, we obtain from the same argument as before that for all $j \in\{1, \ldots, n\}$, $v\left(M_{N_{j}}\right)=\bigcup_{i \in N_{j}} M_{i}$. By construction, there exists also a non-empty set of alternatives which receives one vote from every sub-electorate; that is, $\bigcap_{i \in\{1, \ldots, n\}} v\left(M_{N_{i}}\right) \neq \emptyset$. Hence, we can apply the second part of Consistency in Voters to see that $v\left(M_{N}\right)=\bigcap_{i \in\{1, \ldots, n\}} v\left(M_{N_{i}}\right)$. Both parts, (a) and (b), 
are consistent with our construction of weights if and only if $w_{i}>0$ for all $i \in\{1, \ldots, p\}$.

(3) Let the response profile $M_{N}$ be such that $\left|M_{i}\right| \in\{1, k\}$ for all $i \in N$ and some $1<k \leq p$. Suppose first that $G^{k}\left(M_{N}, x_{i}\right)=G^{k}\left(M_{N}, x_{j}\right)$ for all $i, j \in\{2, \ldots, k+1\}$ and $G^{1}\left(M_{N}, x_{1}\right)+G^{k}\left(M_{N}, x_{2}\right)=|N|$ (the conditions state that the electorate is divided into individuals who either vote for $x_{1}$ or the set $\left.\left\{x_{2}, \ldots, x_{k+1}\right\}\right)$. Now, consider the profile $M^{\prime}$ and the electorate $N^{\prime}$ such that $G^{k}\left(M_{N^{\prime}}^{\prime}, x_{i}\right)=G^{k}\left(M_{N^{\prime}}^{\prime}, x_{j}\right)$ for all $i, j \in\{2, \ldots, k+1\}$, and $G^{1}\left(M_{N^{\prime}}^{\prime}, x_{1}\right)+G^{k}\left(M_{N^{\prime}}^{\prime}, x_{2}\right)=\left|N^{\prime}\right|$. In both response profiles, given Neutrality and the fact that alternatives without any support cannot be elected by Lemma 2, we have only three possible images of $v$ : the singleton $\left\{x_{1}\right\}$, the set $\left\{x_{2}, \ldots, x_{k+1}\right\}$, and the set $\left\{x_{1}, x_{2}, \ldots, x_{k+1}\right\}$. This observation allows us to prove two important claims.

Claim 1 For all profiles $M, M^{\prime}$ and electorates $N, N^{\prime}$ such that $G^{k}\left(M_{N}, x_{i}\right)=$ $G^{k}\left(M_{N}, x_{j}\right)$ and $G^{k}\left(M_{N^{\prime}}^{\prime}, x_{i}\right)=G^{k}\left(M_{N^{\prime}}^{\prime}, x_{j}\right)$ for all $i, j \in\left\{x_{2}, \ldots, x_{k+1}\right\}$, $G^{1}\left(M_{N}, x_{1}\right)+G^{k}\left(M_{N}, x_{2}\right)=|N|$, and $G^{1}\left(M_{N^{\prime}}^{\prime}, x_{1}\right)+G^{k}\left(M_{N^{\prime}}^{\prime}, x_{2}\right)=\left|N^{\prime}\right|$,

(i) if $F_{x_{2}, x_{1}}\left(M_{N} ; k, 1\right)=F_{x_{2}, x_{1}}\left(M_{N^{\prime}}^{\prime} ; k, 1\right)$, then $v\left(M_{N}\right)=v\left(M_{N^{\prime}}^{\prime}\right)$;

(ii) if $F_{x_{2}, x_{1}}\left(M_{N} ; k, 1\right)<F_{x_{2}, x_{1}}\left(M_{N^{\prime}}^{\prime} ; k, 1\right)$ and $\left\{x_{2}, \ldots, x_{k+1}\right\} \subseteq v\left(M_{N}\right)$, then $v\left(M_{N^{\prime}}^{\prime}\right)=\left\{x_{2}, \ldots, x_{k+1}\right\}$;

(iii) if $F_{x_{2}, x_{1}}\left(M_{N} ; k, 1\right)>F_{x_{2}, x_{1}}\left(M_{N^{\prime}}^{\prime} ; k, 1\right)$ and $x_{1} \in v\left(M_{N}\right)$, then $v\left(M_{N^{\prime}}^{\prime}\right)=$ $\left\{x_{1}\right\}$.

Proof: Consider any two profiles $M$ and $M^{\prime}$ and electorates $N$ and $N^{\prime}$ that satisfy the hypothesis of the Lemma. Now, take two electorates $A$ and $B$ of the sizes $G^{1}\left(M_{N^{\prime}}^{\prime}, x_{1}\right) \cdot|N|$ and $G^{1}\left(M_{N}, x_{1}\right) \cdot\left|N^{\prime}\right|$, respectively. Let $\bar{M}_{A}$ and $\bar{M}_{B}$ be two response profiles obtained by replicating $G^{1}\left(M_{N^{\prime}}^{\prime}, x_{1}\right)$-times the response profile $M_{N}$ and $G^{1}\left(M_{N}, x_{1}\right)$-times the response profile $M_{N^{\prime}}^{\prime}$. Namely, the response profile $\bar{M}_{A}$ is the union of $G^{1}\left(M_{N^{\prime}}^{\prime}, x_{1}\right)$-isomorphic copies of $M_{N}$ 
(denoted by $\bar{M}_{A_{t}}$ with $t \in\left\{1, \ldots, G^{1}\left(M_{N^{\prime}}^{\prime}, x_{1}\right)\right\}$ ) and the response profile $\bar{M}_{B}$ is the union of $G^{1}\left(M_{N}, x_{1}\right)$-isomorphic copies of $M_{N^{\prime}}^{\prime}$ (denoted by $\bar{M}_{B_{r}}$ with $\left.r \in\left\{1, \ldots, G^{1}\left(M_{N}, x_{1}\right)\right\}\right)$, where all $A_{t}$ and all $B_{r}$ are disjoint. Then, for all $i \in\{2, \ldots, k+1\}, G^{k}\left(\bar{M}_{A}, x_{i}\right)=G^{k}\left(M_{N}, x_{2}\right) \cdot G^{1}\left(M_{N^{\prime}}^{\prime}, x_{1}\right)$ and $G^{k}\left(\bar{M}_{B}, x_{i}\right)=$ $G^{k}\left(M_{N^{\prime}}^{\prime}, x_{2}\right) \cdot G^{1}\left(M_{N}, x_{1}\right)$.

(i) It follows from the assumptions that $G^{1}\left(\bar{M}_{A}, x_{1}\right)=G^{1}\left(M_{N}, x_{1}\right)$. $G^{1}\left(M_{N^{\prime}}^{\prime}, x_{1}\right)=G^{1}\left(\bar{M}_{B}, x_{1}\right)$ and, for all $i \in\{2, \ldots, k+1\}, G^{k}\left(\bar{M}_{A}, x_{i}\right)=$ $G^{k}\left(\bar{M}_{B}, x_{i}\right)$. Since all alternatives receive the same number of votes from individual approvals of the same size at $\bar{M}_{A}$ and $\bar{M}_{B}$, we obtain from Anonymity that $v\left(\bar{M}_{A}\right)=v\left(\bar{M}_{B}\right)$.

We also obtain from Anonymity that for all $t \in\left\{1, \ldots, G^{1}\left(M_{N^{\prime}}^{\prime}, x_{1}\right)\right\}$ and all $r \in\left\{1, \ldots, G^{1}\left(M_{N}, x_{1}\right)\right\}, v\left(\bar{M}_{A_{t}}\right)=v\left(M_{N}\right)$ and $v\left(\bar{M}_{B_{r}}\right)=v\left(M_{N^{\prime}}^{\prime}\right)$. Then, by iterating on the second part of Consistency in Voters,

$$
v\left(\bar{M}_{A}\right)=v\left(\sum_{t=1}^{G^{1}\left(M_{N^{\prime}}^{\prime}, x_{1}\right)} \bar{M}_{A_{t}}\right)=\bigcap_{t=1}^{G^{1}\left(M_{N^{\prime}}^{\prime}, x_{1}\right)} v\left(\bar{M}_{A_{t}}\right)=v\left(M_{N}\right)
$$

and

$$
v\left(\bar{M}_{B}\right)=v\left(\sum_{r=1}^{G^{1}\left(M_{N}, x_{1}\right)} \bar{M}_{B_{r}}\right)=\bigcap_{r=1}^{G^{1}\left(M_{N}, x_{1}\right)} v\left(\bar{M}_{B_{r}}\right)=v\left(M_{N^{\prime}}^{\prime}\right)
$$

Consequently, it must be the case that $v\left(M_{N^{\prime}}^{\prime}\right)=v\left(M_{N}\right)$.

(ii) It follows from the assumptions that $G^{1}\left(\bar{M}_{A}, x_{1}\right)=G^{1}\left(M_{N}, x_{1}\right)$. $G^{1}\left(M_{N^{\prime}}^{\prime}, x_{1}\right)=G^{1}\left(\bar{M}_{B}, x_{1}\right)$ and, for all $i \in\{2, \ldots, k+1\}, G^{k}\left(\bar{M}_{A}, x_{i}\right)<$ $G^{k}\left(\bar{M}_{B}, x_{i}\right)$. Now, take two response profiles $\hat{M}_{C}$ and $\hat{M}_{D}$ corresponding to the disjoint electorates $C$ and $D$, with the property that for all $x_{i} \in X$ and $j \in\{1, \ldots,|X|\}, G^{j}\left(\hat{M}_{D}, x_{i}\right)=G^{j}\left(\bar{M}_{A}, x_{i}\right)$ and $G^{j}\left(\hat{M}_{C}, x_{i}\right)=G^{j}\left(\bar{M}_{B}, x_{i}\right)-$ $G^{j}\left(\bar{M}_{A}, x_{i}\right)$. By Anonymity, $v\left(\hat{M}_{D}\right)=v\left(\bar{M}_{A}\right)$ and $v\left(\hat{M}_{C}+\hat{M}_{D}\right)=v\left(\bar{M}_{B}\right)$. By the iterated application of the second part of Consistency in Voters and Anonymity, $v\left(\bar{M}_{A}\right)=v\left(M_{N}\right)$ and $v\left(\bar{M}_{B}\right)=v\left(M_{N^{\prime}}^{\prime}\right)$. Hence, $v\left(\hat{M}_{D}\right)=v\left(M_{N}\right)$ and $v\left(\hat{M}_{C}+\hat{M}_{D}\right)=v\left(M_{N^{\prime}}^{\prime}\right)$. 
Since at the response profile $\hat{M}_{C}, G^{k}\left(\hat{M}_{C}, x_{i}\right)=G^{k}\left(\hat{M}_{C}, x_{j}\right)$ for all alternatives $i, j \in\{2, \ldots, k+1\}, G^{k}\left(\hat{M}_{C}, x_{l}\right)=0$ for all $l \notin\{2, \ldots, k+1\}$, and $G^{l}\left(\hat{M}_{C}, x_{i}\right)=0$ for all $x_{i} \in X$ and $l \neq k$, we have that $v\left(\hat{M}_{C}\right)=\left\{x_{2}, \ldots, x_{k+1}\right\}$ by case (B.2) and the fact that $k \leq p$. Since $\left\{x_{2}, \ldots, x_{k+1}\right\} \subseteq v\left(M_{N}\right)$ by assumption and we have already seen before that $v\left(M_{N}\right)=v\left(\hat{M}_{D}\right), v\left(\hat{M}_{C}\right) \cap$ $v\left(\hat{M}_{D}\right)=\left\{x_{2}, \ldots, x_{k+1}\right\}$. This implies that $v\left(\hat{M}_{C}+\hat{M}_{D}\right)=\left\{x_{2}, \ldots, x_{k+1}\right\}$ by the second part of Consistency and Voters. Finally, since we have established earlier that $v\left(\hat{M}_{C}+\hat{M}_{D}\right)=v\left(M_{N^{\prime}}^{\prime}\right)$, we can conclude that $v\left(M_{N^{\prime}}^{\prime}\right)=$ $\left\{x_{2}, \ldots, x_{k+1}\right\}$.

(iii) The proof is similar to the one of part (ii). Thus, it is omitted.

Claim 2 There exist two profiles $M, M^{\prime}$ and two electorates $N, N^{\prime}$ such that (i) $G^{k}\left(M_{N}, x_{i}\right)=G^{k}\left(M_{N}, x_{j}\right) \in(0,|N|)$ and $G^{k}\left(M_{N^{\prime}}^{\prime}, x_{i}\right)=G^{k}\left(M_{N^{\prime}}^{\prime}, x_{j}\right) \in$ $\left(0,\left|N^{\prime}\right|\right)$ for all $i, j \in\left\{x_{2}, \ldots, x_{k+1}\right\}$, (ii) $G^{1}\left(M_{N}, x_{1}\right)+G^{k}\left(M_{N}, x_{2}\right)=|N|$ and $G^{1}\left(M_{N^{\prime}}^{\prime}, x_{1}\right)+G^{k}\left(M_{N^{\prime}}^{\prime}, x_{2}\right)=\left|N^{\prime}\right|$, and (iii) $v\left(M_{N}\right)=\left\{x_{1}\right\}$ and $v\left(M_{N^{\prime}}^{\prime}\right)=$ $\left\{x_{2}, \ldots, x_{k+1}\right\}$.

Proof: Consider the profile $M$ which is such that $M_{1}=\left\{x_{2}, \ldots, x_{k+1}\right\}$ and $M_{i}=\left\{x_{1}\right\}$ for all $i \neq 1$. By Lemma 1 and $k \leq p, v\left(M_{1}\right)=\left\{x_{2}, \ldots, x_{k+1}\right\}$ and $v\left(M_{i}\right)=\left\{x_{1}\right\}$ for all $i \neq 1$. Then, by No-Veto, we know that there exists $t \in \mathbb{N}$ such that $x_{1} \in v\left(M_{2}+\ldots+M_{t}+M_{1}\right)$. Now, since $v\left(M_{t+1}\right)=\left\{x_{1}\right\}$, we can apply the second part of Consistency in Voters in order to see that $v\left(M_{1}+\ldots+M_{t+1}\right)=\left\{x_{1}\right\}$. Using a similar reasoning we can prove that there exists a sufficiently large sequence of individuals such that at the response profile $M_{N^{\prime}}^{\prime}$ where $M_{1}^{\prime}=\left\{x_{1}\right\}$ and $M_{i}^{\prime}=\left\{x_{2}, \ldots, x_{k+1}\right\}$ for all $i \neq 1$, the set of elected alternatives is $\left\{x_{2}, \ldots, x_{k+1}\right\}$.

With the help of Claim 1 and 2, we are now able to construct all strictly positive weights $w_{k}, k \leq p$. This is done in the following claim. Observe that the vector of weights $w$ has one degree of freedom. Hence, we can normalize $w_{1} \equiv 1$ without loss of generality. 
Claim 3 For all $k \leq p$, there exists a strictly positive weight $w_{k} \in \mathbb{R}_{++}$ such that for all profiles $M$ and all electorates $N$ with the property that $G^{k}\left(M_{N}, x_{i}\right)=G^{k}\left(M_{N}, x_{j}\right)$ for all $i, j \in\{2, \ldots, k+1\}$ and $G^{1}\left(M_{N}, x_{1}\right)+$ $G^{k}\left(M_{N}, x_{2}\right)=|N|, x \in v\left(M_{N}\right)$ if and only if $G^{1}\left(M_{N}, x\right)+w_{k} \cdot G^{k}\left(M_{N}, x\right) \geq$ $G^{1}\left(M_{N}, y\right)+w_{k} \cdot G^{k}\left(M_{N}, y\right)$ for all $y \in X$.

Proof: We are going to divide our analysis in four cases. Remember that for response profiles $M_{N}$ satisfying the hypothesis of this claim, $v\left(M_{N}\right) \in$ $\left\{\left\{x_{1}\right\},\left\{x_{1}, \ldots, x_{k+1}\right\},\left\{x_{2}, \ldots, x_{k+1}\right\}\right\}$ by Neutrality and Lemma 2 .

(i) Suppose that the family of voting rules $v$ is such that for all profiles $M$ and all electorates $N$ with the property that $G^{k}\left(M_{N}, x_{i}\right)=G^{k}\left(M_{N}, x_{j}\right)$ for all $i, j \in\{2, \ldots, k+1\}$ and $G^{1}\left(M_{N}, x_{1}\right)+G^{k}\left(M_{N}, x_{2}\right)=|N|, v\left(M_{N}\right)=\left\{x_{1}\right\}$. This contradicts Claim 2 and, therefore, this case cannot be.

(ii) Suppose that the family of voting rules $v$ is such that for all profiles $M$ and all electorates $N$ with the property that $G^{k}\left(M_{N}, x_{i}\right)=G^{k}\left(M_{N}, x_{j}\right)$ for all $i, j \in\{2, \ldots, k+1\}$ and $G^{1}\left(M_{N}, x_{1}\right)+G^{k}\left(M_{N}, x_{2}\right)=|N|, v\left(M_{N}\right)=$ $\left\{x_{2}, \ldots, x_{k+1}\right\}$. This contradicts Claim 2 and, therefore, this case cannot be.

(iii) Suppose that the family of voting rules $v$ is such that for some profiles $M$ and some electorates $N$ with the property that $G^{k}\left(M_{N}, x_{i}\right)=G^{k}\left(M_{N}, x_{j}\right)$ for all $i, j \in\{2, \ldots, k+1\}$ and $G^{1}\left(M_{N}, x_{1}\right)+G^{k}\left(M_{N}, x_{2}\right)=|N|, v\left(M_{N}\right)=$ $\left\{x_{1}, x_{2}, \ldots, x_{k+1}\right\}$. Now, take any other profile $M^{\prime}$ and any other electorate $N^{\prime}$ such that $G^{k}\left(M_{N^{\prime}}^{\prime}, x_{i}\right)=G^{k}\left(M_{N^{\prime}}^{\prime}, x_{j}\right)$ for all $i, j \in\{2, \ldots, k+1\}$ and $G^{1}\left(M_{N}^{\prime}, x_{1}\right)+G^{k}\left(M_{N}^{\prime}, x_{2}\right)=\left|N^{\prime}\right|$. If $F_{x_{2}, x_{1}}\left(M_{N^{\prime}}^{\prime} ; k, 1\right)=F_{x_{2}, x_{1}}\left(M_{N} ; k, 1\right)$, then $v\left(M_{N^{\prime}}^{\prime}\right)=\left\{x_{1}, x_{2}, \ldots, x_{k+1}\right\}$ by the first part of Claim 1. If $F_{x_{2}, x_{1}}\left(M_{N^{\prime}}^{\prime} ; k, 1\right)<$ $F_{x_{2}, x_{1}}\left(M_{N} ; k, 1\right)$, then $v\left(M_{N^{\prime}}^{\prime}\right)=\left\{x_{2}, \ldots, x_{k+1}\right\}$ by the second part of Claim 2. Finally, if $F_{x_{2}, x_{1}}\left(M_{N^{\prime}}^{\prime} ; k, 1\right)>F_{x_{2}, x_{1}}\left(M_{N} ; k, 1\right)$, then $v\left(M_{N^{\prime}}^{\prime}\right)=\left\{x_{1}\right\}$ by the third part of Claim 2. Hence, it has to be the case that $w_{k}=F_{x_{1}, x_{2}}\left(M_{N} ; 1, k\right)$.

(iv) Suppose that the family of voting rules $v$ is such that for all profiles $M$ and all electorates $N$ with the property that $G^{k}\left(M_{N}, x_{i}\right)=G^{k}\left(M_{N}, x_{j}\right)$ for all $i, j \in\{2, \ldots, k+1\}$ and $G^{1}\left(M_{N}, x_{1}\right)+G^{k}\left(M_{N}, x_{2}\right)=|N|, v\left(M_{N}\right) \neq$ $\left\{x_{1}, x_{2}, \ldots, x_{k+1}\right\}$. By Claim 2 , there exist two response profiles $\bar{M}_{A}$ and $\hat{M}_{B}$ 
(both satisfying the hypothesis of the Claim) such that $v\left(\bar{M}_{A}\right)=\left\{x_{1}\right\}$ and $v\left(\hat{M}_{B}\right)=\left\{x_{2}, \ldots, x_{k+1}\right\}$. It follows now from part (ii) and (iii) of Claim 1, NoVeto, and the fact that $\left\{x_{1}\right\}$ and $\left\{x_{2}, \ldots, x_{k+1}\right\}$ are the only possible images of $v$ that $\inf \left\{F_{x_{1}, x_{2}}\left(M_{N} ; 1, k\right): v\left(M_{N}\right)=\left\{x_{1}\right\}\right\}=\sup \left\{F_{x_{1}, x_{2}}\left(M_{N} ; 1, k\right)\right.$ : $\left.v\left(M_{N}\right)=\left\{x_{2}, \ldots, x_{k+1}\right\}\right\}=\delta_{k}$. Hence, it has to be the case that $w_{k}=\delta_{k}$. Observe that $w_{k}$ is an irrational number.

So far, we have shown that if all individuals either vote for $x_{1}$ or the set $\left\{x_{2}, \ldots, x_{k+1}\right\}$, then $v$ is a Size Approval Voting with respect to the vector of weights $w=\left(1, w_{2}, \ldots, w_{|X|}\right)$, where $w_{k} \in \mathbb{R}_{++}$for all $k \in\{2, \ldots, p\}$ and $w_{l}=0$ for all $l>p$. In the final step of this part of the proof we have to show that the constructed weights can be applied at any arbitrary response profile $M_{N}$ satisfying the property $\left|M_{i}\right| \in\{1, k\}$ for all $i \in N$. We start with a claim showing that all alternatives that do not receive the maximal sum of weighted votes are not elected.

Claim 4 For all profiles $M$ and all electorates $N$ such that $\left|M_{i}\right| \in\{1, k\}$ for all $i \in N$ and $x \notin \underset{y}{\operatorname{argmax}}\left\{G^{1}\left(M_{N}, y\right)+w_{k} \cdot G^{k}\left(M_{N}, y\right)\right\}, x \notin v\left(M_{N}\right)$.

Proof: Consider a profile $M$ and an electorate $N$ such that $G^{1}\left(M_{N}, x\right)+w_{k}$. $G^{k}\left(M_{N}, x\right)>G^{1}\left(M_{N}, y\right)+w_{k} \cdot G^{k}\left(M_{N}, y\right)$. We have to show that $y \notin v\left(M_{N}\right)$. To see this, partition the electorate $N$ into six sub-electorates, denoted by $A_{1}, \ldots, A_{6}$. We have that $i \in A_{1}$ if and only if $\{x, y\} \subseteq M_{i}, A_{2}$ is a maximal set such that there exists a bijection $p: A_{2} \rightarrow A_{2}$ satisfying $M_{i}=\{x\}$ and $M_{p(i)}=\{y\}$ (intuitively, $A_{2}$ is a maximal subset in which every individual votes for either only $x$ or for only $y$ and the number of votes is the same for both alternatives), $A_{3}=\left\{i \in N:\{x, y\} \cap M_{i}=\emptyset\right\}$ contains all individuals that neither vote for $x$ nor for $y, A_{4}$ is a maximal set such that there exists a bijection $p: A_{4} \rightarrow A_{4}$ such that $p(i) \neq i$ for all $i \in A_{4},\{x\} \subsetneq M_{i}$, and $\{y\} \subsetneq M_{p(i)}$ (intuitively, this set is constructed in the very same way as $A_{2}$, only that we consider individuals that vote for $k$ alternatives), $A_{5}=\{i \in N$ : $\left|M_{i}\right|=k$ and $\left.i \notin\left(A_{1} \cup A_{3} \cup A_{4}\right)\right\}$ contains the remaining individuals that 
vote for $k$ alternatives and approve either $x$ or $y$, and, finally, $A_{6}=\{i \in N$ : $\left|M_{i}\right|=1$ and $\left.i \notin\left(A_{2} \cup A_{3}\right)\right\}$ is obtained in the very same way as $A_{5}$ only that we consider the individuals that vote exactly for either $x$ or $y$.

Suppose that all subsets are non-empty (otherwise, the proof works out similarly). It follows directly from part (B.2) of this proof that $\{x, y\} \subseteq$ $v\left(M_{A_{1}}\right)$ and $v\left(M_{A_{2}}\right)=\{x, y\}$. Now, we treat the electorates $A_{5}$ and $A_{6}$ jointly. If $x \in M_{i}$ for all $i \in\left(A_{5} \cup A_{6}\right)$, then $v\left(M_{A_{5}}+M_{A_{6}}\right)=\{x\}$ by the second part of Consistency in Voters. Otherwise, consider a profile $M^{\prime}$ and an electorate $B$ of size $\left|A_{5}\right| \cdot\left|A_{5}+A_{6}\right|$. In particular, let the response profile $M_{B}^{\prime}$ be $A_{5}$-isomorphic copies of the response profile $\left(M_{A_{5}}+M_{A_{6}}\right)$. Now, partition the electorate $B$ in $\left|A_{5}\right|$ sub-electorates such that in every $M_{B_{i}}$, with $i \in\left\{1, \ldots,\left|A_{5}\right|\right\}$, there are $\left|A_{6}\right|$ individuals approving exactly one alternative and $\left|A_{5}\right|$ individuals who approve the same $k$ alternatives. Since, by construction, $G^{1}\left(M_{N \backslash\left(A_{5} \cup A_{6}\right)}, x\right)+w_{k} \cdot G^{k}\left(M_{N \backslash\left(A_{5} \cup A_{6}\right)}, x\right)=$ $G^{1}\left(M_{N \backslash\left(A_{5} \cup A_{6}\right)}, y\right)+w_{k} \cdot G^{k}\left(M_{N \backslash\left(A_{5} \cup A_{6}\right)}, y\right)$ and, by assumption, $G^{1}\left(M_{N}, x\right)+$ $w_{k} \cdot G^{k}\left(M_{N}, x\right)>G^{1}\left(M_{N}, y\right)+w_{k} \cdot G^{k}\left(M_{N}, y\right)$, it has to be the case that $G^{1}\left(M_{B_{i}}^{\prime}, x\right)+w_{k} \cdot G^{k}\left(M_{B_{i}^{\prime}}, x\right)>G^{1}\left(M_{B_{i}^{\prime}}, y\right)+w_{k} \cdot G^{k}\left(M_{B_{i}}^{\prime}, y\right)$ for all $i \in$ $\left\{1, \ldots,\left|A_{5}\right|\right\}$. Now, since we have already seen before that $v$ behaves as a Size Approval Voting with vector of weights $w$ at every response profile $M_{N}$ such that $G^{k}\left(M_{N}, x_{i}\right)=G^{k}\left(M_{N}, x_{j}\right)$ for all $i, j \in\left\{x_{2}, \ldots, x_{k+1}\right\}$ and $G^{1}\left(M_{N}, x_{1}\right)+G^{k}\left(M_{N}, x_{2}\right)=|N|$, we can conclude that $x \in v\left(M_{B_{i}}^{\prime}\right)$ and $y \notin v\left(M_{B_{i}}^{\prime}\right)$ for all $i \in\left\{1, \ldots,\left|A_{5}\right|\right\}$. Consequently, $x \in \bigcap_{i=1}^{\left|A_{5}\right|} v\left(M_{B_{i}}^{\prime}\right)$ and $y \notin \bigcap_{i=1}^{\left|A_{5}\right|} v\left(M_{B_{i}}^{\prime}\right)$. Now, we can deduce from the second part of Consistency in Voters that $x \in v\left(M_{B}^{\prime}\right)$ and $y \notin v\left(M_{B}^{\prime}\right)$. Finally, applying this condition again iteratively together with Anonymity yields that $v\left(M_{B}^{\prime}\right)=v\left(M_{A_{5}}+M_{A_{6}}\right)$. Therefore, $x \in v\left(M_{A_{5}}+M_{A_{6}}\right)$ and $y \notin v\left(M_{A_{5}}+M_{A_{6}}\right)$.

Now, if $x \in v\left(M_{A_{4}}\right)$, then $v\left(M_{A_{1}}\right) \cap v\left(M_{A_{2}}\right) \cap v\left(M_{A_{4}}\right) \cap v\left(M_{A_{5}}+M_{A_{6}}\right)=$ $\{x\}$. Hence, by the second part of Consistency in Voters, $v\left(M_{N \backslash A_{3}}\right)=\{x\}$. Since $y \notin M_{i}$ for all $i \in A_{3}$, it follows from the first part of Consistency in Voters that $y \notin v\left(M_{N \backslash A_{3}}+M_{A_{3}}\right)=v\left(M_{N}\right)$. If, however, $x \notin v\left(M_{A_{4}}\right)$, then $y \notin v\left(M_{A_{4}}\right)$ by Neutrality. Consider the profile $\bar{M}$ which is such that 
$\bar{M}_{A_{i}}=M_{A_{i}}$ for all $i \in\{1, \ldots, 6\}$ and $\left\{\bar{M}_{C_{i}}\right\}_{i \in \mathbb{N}}$ is a sequence of response profiles such that $\bar{M}_{C_{i}}$ is an isomorphic copy of $M_{A_{2}}$ and for all $i, j \in \mathbb{N}$, $C_{i} \cap C_{j}=C_{i} \cap A_{2}=\emptyset$. First, by Anonymity, $v\left(\bar{M}_{A_{i}}\right)=v\left(M_{A_{i}}\right)$ for all $i \in\{1, \ldots, 6\}$ and $v\left(\bar{M}_{C_{i}}\right)=\{x, y\}$ for all $i \in \mathbb{N}$. Since $v\left(\bar{M}_{A_{4}}\right) \cap v\left(\bar{M}_{C_{i}}\right)=\emptyset$ for all $i \in \mathbb{N}$, we can apply No-Veto to obtain that there exists $t \in \mathbb{N}$ such that $\{x, y\} \cap v\left(\bar{M}_{C_{1}}+\ldots+\bar{M}_{C_{t}}+\bar{M}_{A_{4}}\right) \neq \emptyset$. Then, by Neutrality, we have that $\{x, y\} \subseteq v\left(\bar{M}_{C_{1}}+\ldots+\bar{M}_{C_{t}}+M_{A_{4}}\right)$. Now, it follows from second part of Consistency in Voters that $v\left(\bar{M}_{C_{1}}+\ldots+\bar{M}_{C_{t}}+\bar{M}_{N \backslash A_{3}}\right)=\{x\}$. Since $v\left(\bar{M}_{C_{1}}+\ldots+\bar{M}_{C_{t}}\right)=\{x, y\}, y \notin v\left(\bar{M}_{N \backslash A_{3}}\right)$ also by the second part of Consistency in Voters (if it was the case that $y \in v\left(\bar{M}_{N \backslash A_{3}}\right)$, then we would have that $y \in v\left(\bar{M}_{C_{1}}+\ldots+\bar{M}_{C_{t}}+\bar{M}_{N \backslash A_{3}}\right)$; but this cannot be because we have already seen that $x$ is the only elected alternative at this response profile). Consequently, $y \notin v\left(\bar{M}_{N \backslash A_{3}}+\bar{M}_{A_{3}}\right)=v\left(\bar{M}_{N}\right)$ by the first part of Consistency in Voters. Thus, $y \notin v\left(M_{N}\right)$.

We finish the third part of the proof by showing that for all profiles $M$ and all electorates $N$ such that $\left|M_{i}\right| \in\{1, k\}$ for all $i \in N, v\left(M_{N}\right)=$ $\operatorname{argmax}\left\{G^{1}\left(M_{N}, y\right)+w_{k} \cdot G^{k}\left(M_{N}, y\right)\right\}$. If only one alternative receives the maximal weighted sum, then it is uniquely elected by Claim 4 and the fact that the image cannot be empty. Suppose therefore that at least two alternatives, $x$ and $y$, receive the maximal weighted sum and $y \notin v\left(M_{N}\right)$. Take another profile $M^{\prime}$ which is such that $M_{1}^{\prime}=\{y\}$ and there exists a succession of disjoint electorates $\left\{N_{i}\right\}_{i \in \mathbb{N}}$ with the property that $M_{N_{i}}^{\prime}$ is an isomorphic copy of $M_{N}$. We have that $v\left(M_{1}^{\prime}\right)=M_{1}^{\prime}$ and $v\left(M_{N_{i}}^{\prime}\right)=v\left(M_{N}\right)$ for all $i \in \mathbb{N}$ by Anonymity. Moreover, by No-Veto, there exists some $t \in \mathbb{N}$ such that $v\left(M_{N}\right) \cap v\left(M_{N_{1}}^{\prime}+\ldots+M_{N_{t}}^{\prime}+M_{1}^{\prime}\right) \neq \emptyset$. But, by construction, alternative $y$ has the unique maximal weighted sum at the response profile $\left(M_{N_{1}}^{\prime}+\ldots+M_{N_{t}}^{\prime}+M_{1}^{\prime}\right)$. Thus, $v\left(M_{N_{1}}^{\prime}+\ldots+M_{N_{t}}^{\prime}+M_{1}^{\prime}\right)=\{y\}$. Therefore, $v\left(M_{N}\right) \cap v\left(M_{N_{1}}^{\prime}+\ldots+M_{N_{t}}^{\prime}+M_{1}^{\prime}\right)=\emptyset$ by assumption. This is a contradiction and concludes the proof of part (B.3). 
(4) Consider any profile $M$ and any electorate $N$. In the same spirit as before, we are going to prove first that if $\sum_{k=1}^{|X|} w_{k} \cdot G^{k}\left(M_{N}, x\right)>\sum_{k=1}^{|X|} w_{k}$. $G^{k}\left(M_{N}, y\right)$, then $y \notin v\left(M_{N}\right)$. To see this divide the electorate $N$ in three sub-electorates: $i \in N_{1}$ if and only if $\{x, y\} \cap M_{i}=\emptyset, N_{2}=\left\{i \in\left(N \backslash N_{1}\right)\right.$ : $\left.\left|M_{i}\right|>p\right\}$, and $N_{3}=\left(N \backslash\left(\left\{N_{1} \cup N_{2}\right\}\right)\right)$. Then, $v\left(M_{N_{2}}\right)=X$ by Lemma 1 and the second part of Consistency in Voters. Given the vector of weights $w=\left(1, w_{2}, \ldots, w_{|X|}\right)$ obtained in part (B.3), construct the vector of rational numbers $q=\left(1, q_{2}, \ldots, q_{|X|}\right)$ in the following way: For all $j=2, \ldots, p$, (i) $q_{j}=w_{j}$ whenever $w_{j} \in \mathbb{Q}$, (ii) $q_{j}=w_{j}+\varepsilon$ whenever $w_{j} \notin \mathbb{Q}$ and $G^{j}\left(M_{N_{3}}, y\right) \geq$ $G^{j}\left(M_{N_{3}}, x\right)$, and (iii) $q_{j}=w_{j}-\varepsilon$ if $w_{j} \notin \mathbb{Q}$ and $G^{j}\left(M_{N_{3}}, y\right)<G^{j}\left(M_{N_{3}}, x\right)$. Additionally, $q_{j}=0$ for all $j>p$. Since the set of rational numbers is dense in the set of real numbers, $\varepsilon$ can be taken sufficiently small to guarantee that $\sum_{k=1}^{|X|} q_{k} \cdot G^{k}\left(M_{N}, x\right)>\sum_{k=1}^{|X|} q_{k} \cdot G^{k}\left(M_{N}, y\right)$. We write $q_{j}=\frac{a_{j}}{b_{j}}$, where $a_{j}, b_{j} \in \mathbb{N}$ and there does not exist a common divisor of $a_{j}$ and $b_{j}$.

Consider the profile $M^{\prime}$ and the electorate $A$ of size $\left|N_{3}\right| \cdot \prod_{j=1}^{p} b_{j}$ such that $M_{A}^{\prime}$ consists of $\prod_{j=1}^{p} b_{j}$ isomorphic copies of $M_{N_{3}}$. Consider moreover the electorate $B$ disjoint from $A$ with the property that $G^{1}\left(M_{B}^{\prime}, x\right)=$ $G^{1}\left(M_{B}^{\prime}, y\right)=\sum_{j=1}^{|X|} q_{j} \cdot G^{j}\left(M_{A}^{\prime}, x\right)$ and $G^{1}\left(M_{B}^{\prime}, x\right)+G^{1}\left(M_{B}^{\prime}, y\right)=|B|$. Obviously, $v\left(M_{B}^{\prime}\right)=\{x, y\}$. Select a sub-electorate $B_{1}$ from the electorate $B$ such that $G^{1}\left(M_{B_{1}}^{\prime}, x\right)=\sum_{j=1}^{|X|} q_{j} \cdot G^{j}\left(M_{A}^{\prime}, y\right)$ and $G^{1}\left(M_{B_{1}}^{\prime}, y\right)=\sum_{j=1}^{|X|} q_{j} \cdot G^{j}\left(M_{A}^{\prime}, x\right)$. Consider a partition of $A,\left\{A_{k}\right\}_{k=1}^{\left|N_{3}\right|}$, and a related partition of $B_{1},\left\{B_{1}^{k}\right\}_{k=1}^{\left|N_{3}\right|}$, satisfying the following conditions for any $k, k^{\prime} \in\left\{1, \ldots,\left|N_{3}\right|\right\}$ :

(i) $\left|A_{k}\right|=\left|A_{k^{\prime}}\right|$;

(ii) $i, j \in A_{k} \Leftrightarrow M_{i}=M_{j}$;

(iii) $\{x, y\} \cap M_{i}=\{x\}$ for all $i \in A_{k} \Leftrightarrow M_{j}=\{y\}$ for all $j \in B_{1}^{k}$ and $\left|B_{1}^{k}\right|=q_{t} \cdot \prod_{j=1}^{p} b_{j}$, where $t=\left|M_{i}\right|$ for all $i \in A_{k}$;

(iv) $\{x, y\} \cap M_{i}=\{y\}$ for all $i \in A_{k} \Leftrightarrow M_{j}=\{x\}$ for all $j \in B_{1}^{k}$ and $\left|B_{1}^{k}\right|=q_{t} \cdot \prod_{j=1}^{p} b_{j}$, where $t=\left|M_{i}\right|$ for all $i \in A_{k} ;$

(v) $\{x, y\} \subseteq M_{i}$ for all $i \in A_{k} \Leftrightarrow$ there exists a bijection $\rho: B_{1}^{k} \rightarrow B_{1}^{k}$ such that if $M_{j}=\{x\}, M_{\rho(j)}=\{y\}$ and $\left|B_{1}^{k}\right|=2 \cdot q_{t} \cdot \prod_{j=1}^{p} b_{j}$, where $t=\left|M_{i}\right|$ for all $i \in A_{k}$. 
Given the construction of the partitions, we have, by the application of Case (B.3), that $x \in v\left(M_{A_{i}}^{\prime}+M_{B_{1}^{i}}^{\prime}\right)$ for all $i \in\left\{1, \ldots,\left|N_{3}\right|\right\}$. Then, we can apply the second part of Consistency in Voters to see that $x \in v\left(M_{B_{1}}^{\prime}+\right.$ $\left.M_{A}^{\prime}\right)$. By construction, $G^{1}\left(M_{B \backslash B_{1}}^{\prime}, x\right)>0$ and $G^{1}\left(M_{B \backslash B_{1}}^{\prime}, y\right)=0$. Then, $v\left(M_{B \backslash B_{1}}^{\prime}\right)=\{x\}$. Hence, by the second part of Consistency in Voters, $v\left(M_{A}^{\prime}+\right.$ $\left.M_{B}^{\prime}\right)=\{x\}$. Applying the second part of Consistency in Voters, we obtain that $y \notin v\left(M_{A}^{\prime}\right)$ (if it was the case that $y \in v\left(M_{A}^{\prime}\right)$, then $y \in v\left(M_{A}^{\prime}\right) \cap v\left(M_{B}^{\prime}\right)$ and, by the second part of Consistency in Voters, $y \in v\left(M_{A}^{\prime}+M_{B}^{\prime}\right)$; but this cannot be because we have already seen before that $\left.v\left(M_{A}^{\prime}+M_{B}^{\prime}\right)=\{x\}\right)$. Since $v\left(M_{A}^{\prime}\right)$ consists of isomorphic copies of $M_{N_{3}}, y \notin v\left(M_{N_{3}}\right)$. Then, by the first part of Consistency in Voters, $y \notin v\left(M_{N}\right)$.

Following the very same argument as in part (B.3), one can finally show that all alternatives for which the weighted sum is maximal must belong to the image of the voting rule. This concludes the proof of part (B.4).

So far, we have shown that there exists a vector of weights $w=\left(w_{k}\right)_{k \leq|X|}$, with $w_{k} \in \mathbb{R}_{+}$, such that $v$ is a Size Approval Voting relative to $w$. Hence, it remains to be shown that the weights are weakly decreasing; that is $w_{k} \geq$ $w_{k+1}$ for all $k \in\{1, \ldots,|X|-1\}$. First, if $k \geq p$, the result follows from the fact that $w_{l}=0$ for all $l>p$. In continuation suppose that there exists a $k<p$ such that $w_{k+1}>w_{k}$. Consider the profile $M$ and the electorate $N=\{1,2\}$ such that $x \in M_{1}, M_{1} \cap M_{2}=\emptyset$, and $\left|M_{1}\right|=\left|M_{2}\right|=k+1$. Then, $x \in v\left(M_{N}\right)$ by Case (B.2). Consider now the response profile $M_{N}^{\prime}$ such that $M_{2}^{\prime}=M_{2}$ and $M_{1}^{\prime}=\left(M_{1} \backslash\{y\}\right)$ with $y \in M_{i}$ and $y \neq x$. Then, since $w_{k+1}>w_{k}$ by assumption, $x \notin v\left(M_{N}^{\prime}\right)$. However, since $x \in\left(M_{1}^{\prime} \cap v\left(M_{N}\right)\right)$ by construction, it follows from Contraction that $M_{1}^{\prime} \cap v\left(M_{N}\right) \subseteq v\left(M_{N}^{\prime}\right)$. This is a contradiction and, therefore, $w_{k} \leq w_{k+1}$.

\section{Independence}

The following examples prove that the properties are independent. 
Consistency in Voters (1): Let $q=\left(1, q_{2}, \ldots, q_{|X|}\right)$ be a vector of weights such that $1>q_{i-1}>q_{i}>0$ for all $i \in\{2, \ldots,|X|-2\}$, and $q_{|X|-1}=q_{X}=$ -1 . Let the family of voting rules $v$ be such that for all profiles $M$ and all electorates $N, x \in v\left(M_{N}\right)$ if and only if $\sum_{k=1}^{|X|} q_{k} \cdot G^{k}\left(M_{N}, x\right) \geq \sum_{k=1}^{|X|} q_{k}$. $G^{k}\left(M_{N}, y\right)$ for all $y \in X$. This family satisfies the second part of Consistency in Voters, Anonymity, Neutrality, Contraction, and No-Veto. The following example shows that it does not satisfy the first part of Consistency in Voters. Let $X=\{x, y, z\}$ and suppose that the response profile $M_{N}$ is such that $M_{1}=\{x\}$ and $M_{2}=\{x, y\}$. Then, $v\left(M_{1}+M_{2}\right)=\{z\}$. Since $v\left(M_{1}\right)=\{x\}$ and $z \notin v\left(M_{2}\right)$ the first part of Consistency in Voters would imply that $z \notin v\left(M_{1}+M_{2}\right)$.

Consistency in Voters (2): Let $n \geq 2$ be any natural number. Let the family of voting rules $v$ be such that for all profiles $M$ and all electorate $N$ of size $|N|<n$ and $G_{y}\left(M_{N}\right)>0$ for some $y \in N, x \in v\left(M_{N}\right)$ if and only if $G_{x}\left(M_{N}\right) \neq 0$. Otherwise, apply Approval Voting. This family satisfies the first part of Consistency in Voters, Anonymity, Neutrality, Contraction, and No-Veto. The following example shows that it does not satisfy the second part of Consistency in Voters. Let $n=3$ and $X=\{x, y, z\}$. Moreover, suppose that the response profile $M_{N}$ is such that $M_{1}=M_{3}=\{x, y\}$ and $M_{2}=M_{4}=\{x, z\}$. Then, $v\left(M_{N}\right)=\{x\}$. But since $v\left(M_{1}+M_{2}\right)=v\left(M_{3}+\right.$ $\left.M_{4}\right)=\{x, y, z\}$, the second part of Consistency in Voters would imply that $v\left(M_{N}\right)=\{x, y, z\}$.

Anonymity: Assign to each individual $i \in \mathbb{N}$ a weight $q_{i} \geq 1$ in such a way that $q_{i} \neq q_{j}$ for some pair $i, j \in \mathbb{N}$. Now, let the family of voting rules $v$ be such that all profiles $M$ and all electorates $N, x \in v\left(M_{N}\right)$ if and only if $\sum_{i \in N: x \in M_{i}} q_{i} \geq \sum_{i \in N: y \in M_{i}} q_{i}$ for all $y \in X$. This family satisfies Consistency in Voters, Neutrality, Contraction, and No-Veto. The following example shows that it is not anonymous. Let $X=\{x, y\}$ and suppose that $N=\{1,2\}$. Moreover, let $q_{1}=2$ and $q_{2}=1$. If $M_{1}=M_{2}^{\prime}=\{x\}$ and $M_{1}^{\prime}=M_{2}=\{y\}$, then $v\left(M_{1}+M_{2}\right)=\{x\}$ and $v\left(M_{1}^{\prime}+M_{2}^{\prime}\right)=\{y\}$. Anonymity would imply 
that $v\left(M_{1}+M_{2}\right)=v\left(M_{1}^{\prime}+M_{2}^{\prime}\right)$.

Neutrality: Assign to each alternative $x_{i} \in X$ a strictly positive weight $q_{i}$ in such a way that $q_{i} \neq q_{j}$ for some pair $x_{i}, x_{j} \in X$. Now, let the family of voting rules $v$ be such that all profiles $M$ and all electorates $N, x \in v\left(M_{N}\right)$ if and only if $q_{x} \cdot G_{x}\left(M_{N}\right) \geq q_{y} \cdot G_{y}\left(M_{N}\right)$ for all $y \in X$. This family satisfies Consistency in Voters, Anonymity, Contraction, and No-Veto. The following example shows that it is not neutral. Let $X=\{x, y\}$ and suppose that $N=\{1,2\}$. Moreover, let $q_{x}=2$ and $q_{y}=1$. If $M_{1}=\{x, y\}$, then $v\left(M_{1}\right)=\{x\}$. Define the permutation $\mu: X \rightarrow X$ to be such that $\mu(x)=y$ and $\mu(y)=x$. Then, $v\left(\mu\left(M_{1}\right)\right)=\{x\}$ and $\mu\left(v\left(M_{1}\right)\right)=\{y\}$. Neutrality would imply that $\mu\left(v\left(M_{1}\right)\right)=v\left(\mu\left(M_{1}\right)\right)$.

Contraction: Let $p=\left(p_{1}, \ldots, p_{|X|}\right)$ be a vector of strictly positive weights such that $p_{i}<p_{i+1}$ for all $i \in\{1, \ldots,|X|-1\}$. The family of voting rules $v$ is such that for all profiles $M \in\left(2^{X}\right)^{\mathbb{N}}$, and all electorates $N, x \in v\left(M_{N}\right) \Leftrightarrow$ $\sum_{k=1}^{|X|} p_{k} \cdot G^{k}\left(M_{N}, x\right) \geq \sum_{k=1}^{|X|} p_{k} \cdot G^{k}\left(M_{N}, y\right)$ for all $y \in X$. This family satisfies Consistency in Voters, Anonymity, Neutrality, and No-Veto. The following example shows that it does not satisfy Contraction. Let $X=\{x, y, z, w\}$ and $N=\{1,2\}$. Suppose two response profiles $M_{N}$ and $M_{N^{\prime}}^{\prime}$ such that $M_{1}=\{x, y\}=M_{1}^{\prime}, M_{2}=\{z, w\}$ and $M_{2}^{\prime}=\{z\}$. Then, $v\left(M_{N}\right)=X$ and $v\left(M_{N^{\prime}}^{\prime}\right)=\{x, y\}$. Contraction would imply that $z \in v\left(M_{N^{\prime}}^{\prime}\right)$.

No-Veto: Let the family of voting rules $v$ be such that $x \in v\left(M_{N}\right)$ if and only if there does not exist $j<|X|$ and $y \in X$ such that (i) $G^{j}\left(M_{N}, y\right)>$ $G^{j}\left(M_{N}, x\right)$ and (ii) $G^{k}\left(M_{N}, y\right) \geq G^{k}\left(M_{N}, x\right)$ for all $1 \leq k<j$. This family satisfies Consistency in Voters, Anonymity, Neutrality, and Contraction. The following example shows that it does not satisfy No-Veto. Let $X=\{x, y, z\}$ and suppose that the response profile is such that $M_{1}=\{x\}$ and $M_{i}=\{y, z\}$ for all $i \geq 2$. Then, $v\left(M_{1}+M_{2}+\ldots+M_{p}\right)=\{x\}$ for all $p \geq 2$. No-Veto would imply that there exists an integer $p \geq 2$ such that $v\left(M_{1}+M_{2}+\ldots+\right.$ $\left.M_{p}\right) \cap\{y, z\} \neq \emptyset$. 


\section{References}

[1] C. Alós-Ferrer, A Simple Characterization of Approval Voting, Social Choice and Welfare 27 (2006), 621-625.

[2] N. Baigent and Y. Xu, Independent Necessary and Sufficient Conditions for Approval Voting, Mathematical Social Sciences 21 (1991), 21-29.

[3] M. Ballester and P. Rey-Biel, Sincere Voting with Cardinal Preferences: Approval Voting, Mimeo (2006).

[4] S. Brams and P. Fishburn, Approval Voting, American Political Science Review 72 (1978), 831-847.

[5] _ Approval Voting, Condorcet's Principle, and Runoff Elections, Public Choice 36 (1981), 89-114.

[6] S. Brams, P. Fishburn, and S. Merrill III, The Responsiveness of Approval Voting: Comments on Saari and van Newenhizen, Public Choice 59 (1988), 121-131.

[7] P. Fishburn, Symmetric and Consistent Aggregation with Dichotomous Preferences, in "Aggregation and Revelation of Preferences" (ed. J. Laffont), North-Holland, Amsterdam, 1978.

[8] _ Axioms for Approval Voting: Direct Proof, Journal of Economic Theory 19 (1978), 180-185.

[9] R Goodin and C. List, A Conditional Defense of Plurality Rule: Generalizing May's Theorem in a Restricted Informational Environment, American Journal of Political Sciences 50 (2006), 940-949.

[10] R. Hoffman, A Model for Strategic Voting, SIAM Journal of Applied Mathematics 42 (1982), 751-761.

[11] J. Massó and M. Vorsatz, Weighted Approval Voting, Mimeo (2006). 
[12] S. Merrill III, Making Multicandidate Elections more Democratic, Princeton, Princeton University Press (1983).

[13] S. Merrill III and J. Nagel, The Effect of Approval Ballotting on Strategic Voting under Alternative Decision Rules, American Political Science Review 81 (1987), 509-524.

[14] R. Nurmi, The Problem of Strategic Behavior under Approval Voting, American Political Science Review 78 (1984), 952-958.

[15] D. Saari and J. van Newenhizen, Is Approval Voting an 'Unmitigated Evil'?: A Response to Brams, Fishburn, and Merill, Public Choice 59 (1988), 132-147.

[16] _ The Problem of Indeterminacy in Approval, Multiple, and Truncated Voting Systems, Public Choice 59 (1988), 101-120.

[17] M. Sertel, Characterizing Approval Voting, Journal of Economic Theory 45 (1988), 207-211.

[18] H. Smith, Aggregation of Preferences with Variable Electorates, Econometrica 41 (1973), 1027-1041.

[19] M. Vorsatz, Approval Voting on Dichotomous Preferences, Social Choice and Welfare (2007), 127-141. 